\title{
The mucosal firewalls against commensal intestinal microbes
}

\author{
Andrew J. Macpherson • Emma Slack • \\ Markus B. Geuking • Kathy D. McCoy
}

Received: 8 June 2009 / Accepted: 10 June 2009 / Published online: 26 August 2009

(C) Springer-Verlag 2009

\begin{abstract}
Mammals coexist with an extremely dense microbiota in the lower intestine. Despite the constant challenge of small numbers of microbes penetrating the intestinal surface epithelium, it is very unusual for these organisms to cause disease. In this review article, we present the different mucosal firewalls that contain and allow mutualism with the intestinal microbiota.
\end{abstract}

Keywords Mucosal firewalls · Commensal intestinal microbes $\cdot$ Lower intestine $\cdot$ Microbiota $\cdot$ Host-microbial relationship

\section{Introduction}

The lower intestine is colonized with a very dense microbiota of up to $10^{12}$ colony-forming units per gram of intestinal contents. This density is considerably higher than found in most other microbiological populations, including soils and subsurfaces [1]. It also means that the total load (about $10^{14}$ ) of microorganisms in the human intestine is an order of magnitude greater than the cells in the body (about $10^{13}$ ).

Many of the beneficial effects of the intestinal microbiota have been well known for decades. They are important to salvage energy from otherwise indigestible foods, they take up space in the microbial niche and limit access for pathogens, and they provide the host with

A. J. Macpherson $(\bowtie) \cdot$ E. Slack $\cdot$ M. B. Geuking $\cdot$ K. D. McCoy DKF, Maurice Müller Laboratories,

Department of Visceral Surgery and Medicine,

University of Bern,

Room G801, Murtenstrasse 35,

CH3010 Bern, Switzerland

e-mail: andrew.macpherson@insel.ch vitamins. These interactions were first discovered in the first half of the twentieth century after it became possible to breed experimental animals in germ-free conditions and so animals with and without an intestinal microbiota could be compared [2]. Subsequent experiments have shown that the intestinal microbiota also shapes the host, for example, Peyer's patches and intestinal lymphoid follicles are hypoplastic under germ-free conditions [3]. The intestinal contents of IgA-producing plasma cells [4], CD4 lamina propria $\mathrm{T}$ cells, and intraepithelial $\alpha \beta \mathrm{CD} 8 \mathrm{~T}$ cells carrying the $\alpha \beta \mathrm{T}$ cell receptor [5] are only present in normal quantities in mice with a normal commensal intestinal microbiota. Germ-free experimentation with strains of mice carrying targeted genetic deficiencies or using modern techniques to measure gene expression have shown that the relationship between host and microbiota is even extensive than originally thought, affecting not only immune cell populations and intestinal epithelial gene expression [6,7], but also the function of most body systems and regulation of central body metabolism $[2,8]$.

Although most individuals coexist harmoniously with commensal microbiota, hardly noticing the presence of these little passengers except during visits to the toilet, much intestinal disease directly or indirectly involves imbalance in the relationship. Crohn's disease can arise from mutations in the NOD2/CARD15 gene [9-11] that senses the bacterial cell wall breakdown molecule muramyl dipeptide [12], and both clinical and animal model evidence implicate an imbalance in the host-microbial relationship as a key factor that underlies the condition [13]. Functional intestinal disease can arise from failed absorption of dietary carbohydrates in the jejunum with subsequent bacterial fermentation when the carbon sources reach the terminal ileum or colon. Abnormal colonization of the upper small intestine or blind intestinal loops with commensal organ- 
isms results in digestive disturbance and functional symptoms: this can also be a secondary consequence of drug treatments or motility disturbances in systemic disease. Intestinal bacteria also play an adjuvant role in intestinal tumors and enteropathies induced by antibiotics or other drugs [14].

Although the direct consequences of immunodeficiencies or dysfunction in the mucosal immune system are important in generating intestinal pathology from disrupted host-microbial mutualism, it is also important to consider how disruption of the barriers between host and microbe affect systemic pathology. It is clear that individuals that are compromised through immunosuppression through drugs, radiotherapy, or immune deficiency have increased susceptibility to sepsis from their commensal microbiota [15]. This review considers the barriers to commensal penetration from the intestinal lumen to the underlying tissues of the body and the possible relevance of these to human disease.

\section{Firewalls against commensal intestinal bacteria}

The epithelial cell layer

The primary barrier against the penetration of microorganisms and large molecules from the lumen of the intestine is the simple epithelium of a single layer of enterocytes, overlaid with mucus and joined together by junctional complexes. Healthy barrier function also depends on crosstalk with intraepithelial lymphocytes, which are required for the production of trophic factors and repair of damaged or dead cells [16, 17]. The importance of this barrier can be shown from spontaneous intestinal inflammation which occurs in mice colonized with intestinal bacteria that carry genetic deficiencies in mucin production or formation of the intraepithelial cell complexes [18, 19].

In clinical practice, it is possible to measure the transepithelial cellular permeability to macromolecules using noninvasive tests of selective sugar permeability, which depend on differential excretion of the test sugars (e.g., lactulose/rhamnose) in the urine. These measurements show that everyday challenges to the intestine result in increased permeability across the intestinal epithelial layer. Examples include subclinical infections, intake of alcohol, spicy foods, drugs such as the nonsteroidal anti-inflammatory agents, and even stress [20]. It is hardly surprising that more severe challenges to epithelial cells, including radiation damage, acute toxicity from chemotherapeutic agents, and graft-versus-host disease, have even more dramatic effects on permeability [20]. In humans, it is hard to distinguish the contribution of penetration of intestinal bacteria or their molecules from penetration of other molecular components of the luminal contents, although pretreatment with antibiotics to reduce the luminal load of intestinal bacteria is routinely used as part of the protocol in bone marrow transplantation and to treat patients with enteropathy generated with nonsteroidal anti-inflammatory drugs. In mice, most models of chronic intestinal inflammation that have been studied are either abolished or dramatically attenuated, yet there is evidence that the integrity of the epithelial barrier actually requires Toll-like receptor signaling (TLR) [21, 22].

Apart from the physical barrier of the epithelial cell layer and the overlying mucus, epithelial cells secrete small antibacterial peptides (defensins and cathelicidins) and one of the defects generated by deficient NOD2/CARD15 signaling in some cases of Crohn's disease is failure of differentiation of the epithelial Paneth cell lineage, which secrete these peptides [23-25]. A further genetic defect identified in humans is a variation in the ATG16L1 gene that mediates autophagy [26]. This mutant protein does not appear to abrogate nonselective autophagy (the process of formation of double-membrane cytosolic vesicles that sequester parts of the cytoplasm and deliver them to the lysosome for degradation). Instead, there appears to be a defect in the exocytic pathway of Paneth cells, resulting in impaired secretion of antibacterial peptides and lysozyme [27].

The epithelial cell layer is also subject to a continuous flow of $\operatorname{IgA}$ secretion through attachment of $\operatorname{IgA}$ to the polymeric immunoglobulin receptor $(\mathrm{pIgR})$ at the epithelial basolateral surface and delivery through transepithelial vesicular shuttling to the apical (luminal) surface [28, 29]. This continuous secretion of immunoglobulin has a high capacity - typically $3 \mathrm{~g} \mathrm{IgA/day} \mathrm{in} \mathrm{humans} \mathrm{-} \mathrm{and} \mathrm{presum-}$ ably contributes to clearance of the small number of bacteria that penetrate the epithelial cell layer. The evidence for this is largely indirect: polarized cell monolayers can achieve IgA-dependent clearance of viruses [30, 31], and there is immunoglobulin-dependent clearance of rotavirus in vivo [32]. When the system does not work, in pathogenfree pIgR-deficient mice colonized with a commensal microbiota, intestinal dysfunction can be shown by a protein-losing enteropathy [33]. Furthermore, one of the cardinal clinical features of humans with common variable immunodeficiency, lacking all isotypes of immunoglobulin, is chronic intestinal inflammation which may present in adult life and be confused with inflammatory bowel disease or celiac sprue [34].

\section{Subepithelial macrophages}

As described in the previous section, the epithelial permeability barrier is far from perfect in normal human life, yet we still tolerate our intestinal microbiota despite 
drinking alcohol and taking nonsteroidal anti-inflammatory drugs to mitigate the consequences. There are abundant resident macrophages underneath the surface epithelium, which also to contribute to the elimination of the small number of microorganisms that reach the basolateral surface of the intestinal epithelium through phagosome biocidal killing mechanisms involving free radical peroxidation [35]. Intestinal resident macrophages are normally relatively noninflammatory with low expression of bacterial receptor molecules, including TLR2, TLR4, and the CD14 lipopolysaccharide receptor, although increased IL-1 inflammatory responses are seen in the setting of mutations of the ATG16L1 autophagy. Lamina propria CD4 T cells have a limited effect on avoiding penetration of bacteria through the intestinal firewall mainly by cytokine-dependent activation of intestinal macrophages [36-38].

There are three indirect lines of evidence that support the role of intestinal macrophages in eliminating penetrant commensal microorganisms. First, intestinal inflammation occurs in colonized-but not germ-free-mice that are deficient in the Stat3 signaling pathway from cytokines of the IL-6 family in macrophages and neutrophils and, therefore, cannot be properly activated [39]. Secondly, mice deficient for biocidal killing mechanisms as a result of targeted deficiency in the production of superoxide and nitric oxide radicals are highly susceptible to spontaneous death through commensal sepsis soon after weaning [40]. Chronic granulomatous disease in humans, which is also caused by the inability to generate reactive superoxide radicals, results in a severe intestinal enteropathy as well as systemic opportunistic infections [41, 42]. Thirdly, many intestinal bacterial pathogens, including Salmonella, Shigella, and Yersinia, have strategies to evade macrophage biocidal activation and establish a facultative intracellular existence encoded by their genomic pathogenicity islands as a critical part of their pathogenic potential [43]. Presumably, deficiency in the innate immune pathways of these cells, such as in NOD2 Crohn's disease, is relevant for human intestinal inflammation. It has been increasingly recognized that many immunodeficiencies may present in adult life with a narrow phenotype (without multiple opportunistic infections), and different potential subtle alterations of signaling in this cell type may be a promising avenue to explain the large variety of different phenotypes in human inflammatory bowel disease [44, 45].

Dendritic cell commensal sampling and the mesenteric lymph node barrier

A barrier that totally excluded commensal intestinal microorganisms or their breakdown molecules would not allow induction of responses by the intestinal mucosal immune system against these organisms. It follows that some leakiness of the epithelial cell barrier is required to allow the immune system to sense microorganisms in the intestine. This is achieved in several ways. First, a small number of commensal bacteria can penetrate through the specialized epithelium, rich in $\mathrm{M}$ cells, that overlies the intestinal Peyer's patches and lymphoid follicles. These bacteria are sampled by intestinal dendritic cells (DC) which are capable of inducing both $\mathrm{B}$ and $\mathrm{T}$ cell mucosal responses [46]. Alternatively, processes of DC can penetrate through the epithelial junctional complexes to sample bacteria in the mucus layer or the lumen [47].

DC that have sampled intestinal bacteria (and induced intestinal mucosal immune responses) are rather poor at killing the sentinel bacteria, especially in comparison with intestinal macrophages that lie in clusters underneath the surface epithelium. However, DC laden with commensal intestinal bacteria can home to the mesenteric lymph nodes, but do not penetrate further to reach systemic tissues elsewhere in the body [46]. It is assumed that the short lifespan of the DC mean that they die in the mesenteric lymph nodes and the bacteria they carry are released and killed by resident macrophages. The net result of this is that a mucosal immune response can be induced locally in the intestinal mucosa, but penetration of the inducing DC carrying intestinal bacteria into central systemic body tissues is not required. In other words, the mesenteric lymph nodes act as a firewall to limit mucosal immune induction system to the mucosal immune system itself and limit exposure to commensals elsewhere in the body.

It is clear that the firewall against commensal intestinal bacteria functions in multiple layers. What relevance may this have for human intestinal inflammatory pathogenesis? There is recognition that alterations in immune function or immunodeficiency may be more subtle than classically described with the phenotype or disease only becoming apparent in adult life and with a restricted range of microorganisms that are responsible for the immunopathology $[45,48]$. This new paradigm may be very relevant for many of the potential underlying defects for inflammatory bowel disease where the firewalls against the abundant microflora are tested continuously throughout life. Many subclinical intestinal inflammatory conditions also exist with unclear etiology that do not fit into the recognized criteria for diagnosis of Crohn's disease or ulcerative colitis: these may also be explainable in part by deficiencies of one of the firewall layers that limit the penetration of our abundant commensal intestinal microbiota.

\section{References}

1. Whitman WB, Coleman DC, Wiebe WJ (1998) Prokaryotes: the unseen majority. Proc Natl Acad Sci U S A 95:6578-6583 
2. Smith K, McCoy KD, Macpherson AJ (2007) Use of axenic animals in studying the adaptation of mammals to their commensal intestinal microbiota. Semin Immunol 19:59-69

3. Macpherson AJ, Harris N (2004) Interactions between commensal intestinal bacteria and the immune system. Nat Rev Immunol 4:478-485

4. Benveniste J, Lespinats G, Salomon J (1971) Serum and secretory IgA in axenic and holoxenic mice. J Immunol 107:1656-1662

5. Guy-Grand D, Griscelli C, Vassalli P (1978) The mouse gut T lymphocyte, a novel type of T cell. Nature, origin, and traffic in mice in normal and graft-versus-host conditions. J Exp Med 148:1661-1677

6. Hooper LV, Wong MH, Thelin A, Hansson L, Falk PG, Gordon JI (2001) Molecular analysis of commensal host-microbial relationships in the intestine. Science 291(5505):881-884

7. Hooper LV, Stappenbeck TS, Hong CV, Gordon JI (2003) Angiogenins: a new class of microbicidal proteins involved in innate immunity. Nat Immunol 4:269-273

8. Backhed F, Ding H, Wang T, Hooper LV, Koh GY, Nagy A, Semenkovich CF, Gordon JI (2004) The gut microbiota as an environmental factor that regulates fat storage. Proc Natl Acad Sci U S A 101:15718-15723

9. Ogura Y, Bonen DK, Inohara N, Nicolae DL, Chen FF, Ramos R, Britton H, Moran T, Karaliuskas R, Duerr RH et al (2001) A frameshift mutation in NOD2 associated with susceptibility to Crohn's disease. Nature 411(6837):603-606

10. Hugot JP, Chamaillard M, Zouali H, Lesage S, Cezard JP, Belaiche J, Almer S, Tysk C, O'Morain CA, Gassull M et al (2001) Association of NOD2 leucine-rich repeat variants with susceptibility to Crohn's disease. Nature 411(6837):599-603

11. Hampe J, Cuthbert A, Croucher PJP, Mirza MM, Mascheretti S, Fisher S, Frenzel H, King K, Hasselmeyer A, Macpherson AJ et al (2001) Association between insertion mutation in NOD2 gene and Crohn's disease in German and British populations. Lancet 357:1925-1928

12. Girardin SE, Boneca IG, Viala J, Chamaillard M, Labigne A, Thomas G, Philpott DJ, Sansonetti PJ (2003) Nod2 is a general sensor of peptidoglycan through muramyl dipeptide (MDP) detection. J Biol Chem 278:8869-8872

13. Mueller C, Macpherson AJ (2006) Layers of mutualism with commensal bacteria protect us from intestinal inflammation. Gut 55:276-284

14. Rana SV, Bhardwaj SB (2008) Small intestinal bacterial overgrowth. Scand J Gastroenterol 43:1030-1037

15. van der Meer JW, Guiot HF, van den Broek PJ, van Furth R (1984) Infections in bone marrow transplant recipients. Semin Hematol 21:123-140

16. Boismenu R, Havran WL (1994) Modulation of epithelial cell growth by intraepithelial gamma delta $\mathrm{T}$ cells. Science 266 (5188):1253-1255

17. Poussier P, Ning T, Banerjee D, Julius M (2002) A unique subset of self-specific intraintestinal T cells maintains gut integrity. J Exp Med 195:1491-1497

18. Hermiston ML, Gordon JI (1995) Inflammatory bowel disease and adenomas in mice expressing a dominant negative $\mathrm{N}$-cadherin. Science 270(5239):1203-1207

19. Heazlewood CK, Cook MC, Eri R, Price GR, Tauro SB, Taupin D, Thornton DJ, Png CW, Crockford TL, Cornall RJ et al (2008) Aberrant mucin assembly in mice causes endoplasmic reticulum stress and spontaneous inflammation resembling ulcerative colitis. PLoS Med 5:e54

20. Bjarnason I, Macpherson AJ, Hollander D (1995) Intestinal permeability: an overview. Gastroenterology 108:1566-1581

21. Rakoff-Nahoum S, Paglino J, Eslami-Varzaneh F, Edberg S, Medzhitov R (2004) Recognition of commensal microflora by Toll-like receptors is required for intestinal homeostasis. Cell 118:229-241
22. Gibson DL, Ma C, Bergstrom KS, Huang JT, Man C, Vallance BA (2008) MyD88 signalling plays a critical role in host defence by controlling pathogen burden and promoting epithelial cell homeostasis during Citrobacter rodentiuminduced colitis. Cell Microbiol 10:618-631

23. Salzman NH, Bevins CL (2008) Negative interactions with the microbiota: IBD. Adv Exp Med Biol 635:67-78

24. Salzman NH, Underwood MA, Bevins CL (2007) Paneth cells, defensins, and the commensal microbiota: a hypothesis on intimate interplay at the intestinal mucosa. Semin Immunol 19:70-83

25. Wehkamp J, Wang G, Kubler I, Nuding S, Gregorieff A, Schnabel A, Kays RJ, Fellermann K, Burk O, Schwab M et al (2007) The Paneth cell alpha-defensin deficiency of ileal Crohn's disease is linked to Wnt/Tcf-4. J Immunol 179:3109-3118

26. Rioux JD, Xavier RJ, Taylor KD, Silverberg MS, Goyette P, Huett A, Green T, Kuballa P, Barmada MM, Datta LW et al (2007) Genome-wide association study identifies new susceptibility loci for Crohn disease and implicates autophagy in disease pathogenesis. Nat Genet 39:596-604

27. Cho JH (2008) The genetics and immunopathogenesis of inflammatory bowel disease. Nat Rev Immunol 8:458-466

28. Brandtzaeg P, Prydz H (1984) Direct evidence for an integrated function of $\mathrm{J}$ chain and secretory component in epithelial transport of immunoglobulins. Nature 311:71-73

29. Macpherson AJ, Hunziker L, McCoy K, Lamarre A (2001) IgA responses in the intestinal mucosa against pathogenic and nonpathogenic microorganisms. Microbes Infect 3:1021-1035

30. Mazanec MB, Coudret CL, Fletcher DR (1995) Intracellular neutralization of influenza virus by immunoglobulin A antihemagglutinin monoclonal antibodies. J Virol 69:1339-1343

31. Mazanec MB, Kaetzel CS, Lamm ME, Fletcher D, Nedrud JG (1992) Intracellular neutralization of virus by immunoglobulin A antibodies. Proc Natl Acad Sci U S A 89:6901-6905

32. Burns JW, Siadat-Pajouh M, Krishnaney AA, Greenberg HB (1996) Protective effect of rotavirus VP6-specific IgA monoclonal antibodies that lack neutralizing activity. Science 272:104-107

33. Johansen FE, Pekna M, Norderhaug IN, Haneberg B, Hietala MA, Krajci P, Betsholtz C, Brandtzaeg P (1999) Absence of epithelial immunoglobulin A transport, with increased mucosal leakiness, in polymeric immunoglobulin receptor/secretory componentdeficient mice. J Exp Med 190:915-922

34. Chapel H, Lucas M, Lee M, Bjorkander J, Webster D, Grimbacher B, Fieschi C, Thon V, Abedi MR, Hammarstrom L (2008) Common variable immunodeficiency disorders: division into distinct clinical phenotypes. Blood 112:277-286

35. Schenk M, Mueller C (2007) Adaptations of intestinal macrophages to an antigen-rich environment. Semin Immunol 19:84-93

36. Maddaus MA, Wells CL, Platt JL, Condie RM, Simmons RL (1988) Effect of $T$ cell modulation on the translocation of bacteria from the gut and mesenteric lymph node. Ann Surg 207:387-398

37. Gautreaux MD, Gelder FB, Deitch EA, Berg RD (1995) Adoptive transfer of $\mathrm{T}$ lymphocytes to T-cell-depleted mice inhibits Escherichia coli translocation from the gastrointestinal tract. Infect Immun 63:3827-3834

38. Owens WE, Berg RD (1980) Bacterial translocation from the gastrointestinal tract of athymic $(\mathrm{nu} / \mathrm{nu})$ mice. Infect Immun 27:461-467

39. Takeda K, Clausen BE, Kaisho T, Tsujimura T, Terada N, Forster I, Akira S (1999) Enhanced Th1 activity and development of chronic enterocolitis in mice devoid of Stat3 in macrophages and neutrophils. Immunity 10:39-49

40. Shiloh MU, MacMicking JD, Nicholson S, Brause JE, Potter S, Marino M, Fang F, Dinauer M, Nathan C (1999) Phenotype of 
mice and macrophages deficient in both phagocyte oxidase and inducible nitric oxide synthase. Immunity 10:29-38

41. Marks DJ, Miyagi K, Rahman FZ, Novelli M, Bloom SL, Segal AW (2009) Inflammatory bowel disease in CGD reproduces the clinicopathological features of Crohn's disease. Am J Gastroenterol 104:117-124

42. Segal BH, Romani L, Puccetti P (2009) Chronic granulomatous disease. Cell Mol Life Sci 66:553-558

43. Sansonetti P (2001) Phagocytosis of bacterial pathogens: implications in the host response. Semin Immunol 13:381390

44. Casanova JL, Abel L (2007) Primary immunodeficiencies: a field in its infancy. Science 317(5838):617-619
45. Casanova JL, Fieschi C, Zhang SY, Abel L (2008) Revisiting human primary immunodeficiencies. J Intern Med 264:115-127

46. Macpherson AJ, Uhr T (2004) Induction of protective IgA by intestinal dendritic cells carrying commensal bacteria. Science 303:1662-1665

47. Niess JH, Brand S, Gu X, Landsman L, Jung S, McCormick BA, Vyas JM, Boes M, Ploegh HL, Fox JG et al (2005) CX3CR1mediated dendritic cell access to the intestinal lumen and bacterial clearance. Science 307(5707):254-258

48. Casanova JL, Fieschi C, Bustamante J, Reichenbach J, Remus N, von Bernuth H, Picard C (2005) From idiopathic infectious diseases to novel primary immunodeficiencies. J Allergy Clin Immunol 116:426-430 